\title{
EFFECT OF BODY POSITION DURING WHOLE BODY VIBRATION ON ACUTE JUMPING PERFORMANCE
}

\author{
Celil Kaçoğlu, Barış Gürol \\ Anadolu University Faculty of Sport Sciences, Coach Training, Eskisehir, Turkey
}

\begin{abstract}
Background. The aim of the study was to investigate the acute effect of whole-body vibration (WBV) during heel raised and standing squat position on squat (SJ) and countermovement jump (CMJ) heights.

Methods. Twenty four physically active sport science students are voluntarily participated in this study. Randomized, counterbalanced, crossover study was used in this study and all subjects completed two trials that were plantar $\left(25-30^{\circ}\right)$ and dorsal $\left(5-10^{\circ}\right)$ flexion squats. WBV exercises were performed on a vibration plate at $26 \mathrm{~Hz}$ frequency, $4 \mathrm{~mm}$ amplitude. Jumping performances were assessed with and without WBV conditions. Subjects executed WBV condition treatment on static plantar or dorsal flexion half squat position ( $45^{\circ} \mathrm{knee}$ angle) for $3 \times 60 \mathrm{~s}$ with $60 \mathrm{~s}$ rest between sets.

Results. There was no statistically significant two-way interaction between treatments and times for SJ and CMJ $(p>.05)$. SJ and CMJ after the WBV were significantly higher than without WBV condition $(p<.05)$. SJ and CMJ heights were higher than baseline values without WBV.

Conclusion. These results indicate that there were no differences between WBV during plantar and dorsal flexion squat position on SJ and CMJ heights. Regardless of different muscle length squat position during WBV, there were little but significant differences $(\sim 1 \mathrm{~cm})$ on SJ and CMJ heights after WBV. According to these results it can be said that WBV had a statistically significant acute effect on jumping, but different plantar-flexor muscle length squat position on vibration plate during WBV did not have any effect on jumping performance.
\end{abstract}

Keywords: whole body vibration, acute effect, body position, jump performance.

\section{INTRODUCTION}

$\mathrm{W}$ hole body vibration (WBV) is a popular training method of athletic performance for athletes in many sports branches. Vibration is a mechanical stimulus characterized by an oscillatory motion (Cardinale \& Bosco, 2003). This training method was developed for Soviet cosmonauts to recover from loss of muscle and bone during immobilization and space flight (Rittweger et al., 2002). During WBV, activation of the leg muscles varied between 12.6 and $82.4 \%$ of MVC values (Roelants, Verschueren, Delecluse, Levin, \& Stijnen, 2006) and vibration occurring with gravitational changes to the body can reach up to $14 \mathrm{~g}$ (Bosco et al., 1999; Cardinale $\&$ Bosco, 2003). Muscle contraction and gravity provides a mechanical stimulus responsible for the development of muscle structure in exercise and training (Bosco et al., 1998). It has been hypothesized that low-amplitude, low-frequency mechanical stimulation of the human body is a safe and effective way to improve muscle strength (Cardinale \& Bosco, 2003; Torvinen et al., 2002).

The principle of this exercise modality is to perform different type volitional movement on a vibrating platform moving up and down or side to side at different frequency and amplitude. The mechanical action of vibration is to produce fast and short changes in the length of the muscletendon complex (Cardinale \& Bosco, 2003). This vibration movement evokes a stretch reflex action called tonic vibration reflex that is based on stretch reflex response and this reflex activity 
is mainly attributable to muscle spindle Ia fibres (Romaiguere, Vedel, Azulay, \& Pagni, 1991). This reflex response excites more motor units than similar movement without vibration and leg extensor muscles (soleus, gastrocnemius medialis and rectus femoris muscles) seem to be caused by vibration induced stretch reflexes during WBV (Ritzmann, Gollhofer, \& Kramer, 2010).

Some studies focused on body position during WBV. According to these studies, knee flexion of $90^{\circ}$ during WBV is associated with a greater magnitude of vibration to the calf compared to the knee flexion of $30^{\circ}$, and $90^{\circ}$ squat position may be useful for conducting vibration to the calf (Tsukahara et al., 2016). Abercromby et al. (2007) indicated that static squat position caused higher meuromuscular responses compared to dynamic squatting. Ritzmann, Gollhofer, and Kramer (2013) stated that at knee flexion of $60^{\circ}$, forefoot stance can be beneficial for knee extensors and plantar flexors with respect to EMG activity.

Vibration effects mostly on muscle spindle and the knowledge of muscle lengthening during vibration may be a prerequisite for eliciting stretch reflexes (Cochrane, Loram, Stannard, \& Rittweger, 2009). However acute effects of muscle length during WBV on athletic performance are not widely discussed in literature. Therefore, the purpose of this study was to assess the acute effect of two different squat positions with short or long plantar-flexor muscle length during WBV on squat (SJ) and countermovement jump (CMJ) heights and our hypothesis was that body position with regard to plantar-flexor muscle length during WBV would affect acute jump performance.

\section{METHODS}

Twenty four physically active sport science students at Anadolu University voluntarily participated in this study. Randomized, counterbalanced, crossover study was conducted and all subjects completed two trials that were plantar $\left(25-30^{\circ}\right)$ and dorsal $\left(5-10^{\circ}\right)$ flexion squats with and without WBV, and sufficient time was given between trials. WBV exercises were performed on a vertical vibration platform (Pro 5 Airdaptive Model, Power-Plate ${ }^{\circledR}$, USA) at $26 \mathrm{~Hz}$ frequency, $4 \mathrm{~mm}$ amplitude (Figure 1). Trials were carried out on different days and between tests minimum 2 days were given for rest. Each test day started with standard warm-up routines including of concentric, ballistic, dynamic contractions following $5 \mathrm{~min}$ of running on a treadmill at moderate intensity. After the warm up, about a 5-10 min resting period was given to subjects, and then jumping performance was consudered as a pre-test measurement. Each subject executed WBV condition treatment on static plantar or dorsal flexion squat position (knee flexed $45^{\circ}$ ) for $3 \times 60 \mathrm{~s}$ with a $60 \mathrm{~s}$ rest between sets. Three minutes were given after completing WBV and then SJ and CMJ heights were tested with a mat working with a flight time recorder and three trials were performed with a 1 min rest period. Pre-test measurements for exercising without WBV were taken the same way as described above before the WBV sessions. The best of three trials were taken for statistical analysis. Two-way repeated measures ANOVA was used to determine whether there were differences between the values of two treatments with and without WBV over time in SJ and CMJ.
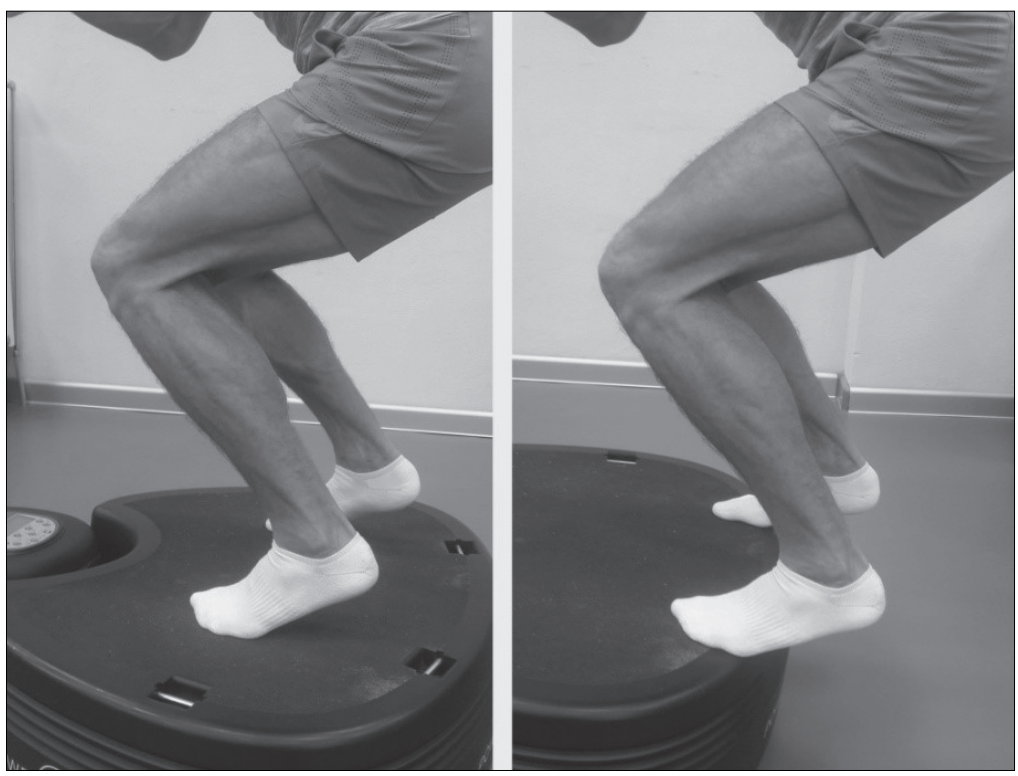

Figure 1. Two squat positions during WBV (modified from Gojanovic, Feihl, Liaudet, Gremion, \& Waeber, 2011) 
SJ and CMJ variables were normally distributed by Shapiro-Wilk's test of studentized residuals $(p>.05)$ and there were no any outliers. Mauchly's sphericity was met because sphericity is always met for two levels of a repeated measure factor. All the data are presented as mean \pm standard deviation.

\section{RESULTS}

There was no statistically significant twoway interaction between treatment (WBV during plantar or dorsal flexion squat) and time (pre or post) for SJ, $F(1,23)=1.246, p>.05$ and CMJ, $F(1,23)=0.910, p>.05$. According to these results the effect of different plantar-flexor muscle length squat position during WBV on jump heights was not different. Jump heights did not change significantly over time depending on the type of different plantar-flexor muscle length conditions. The main effect of treatment showed a statistically significant difference in SJ heights $F(1,23)=$ $16.066, p=.001$ and CMJ heights $F(1,23)=14.502$, $p=.001$ between times. The main effect of time showed that there was a statistically significant difference in $\mathrm{SJ}$ and $\mathrm{CMJ}$ heights between time points $F(1,23)=2.089, p<.05$. Bonferroni post hoc test results indicated that $\mathrm{SJ}$ and $\mathrm{CMJ}$ heights were higher $(1.2,1.4 \mathrm{~cm}$; respectively) than the pre-test values (Figure 2) after WBV regardless of different muscle length squat position.
Figure 2. CMJ and SJ jumping heights before and after WBV in plantar and dorsal squat positions

Note. ${ }^{*} p<.05$.

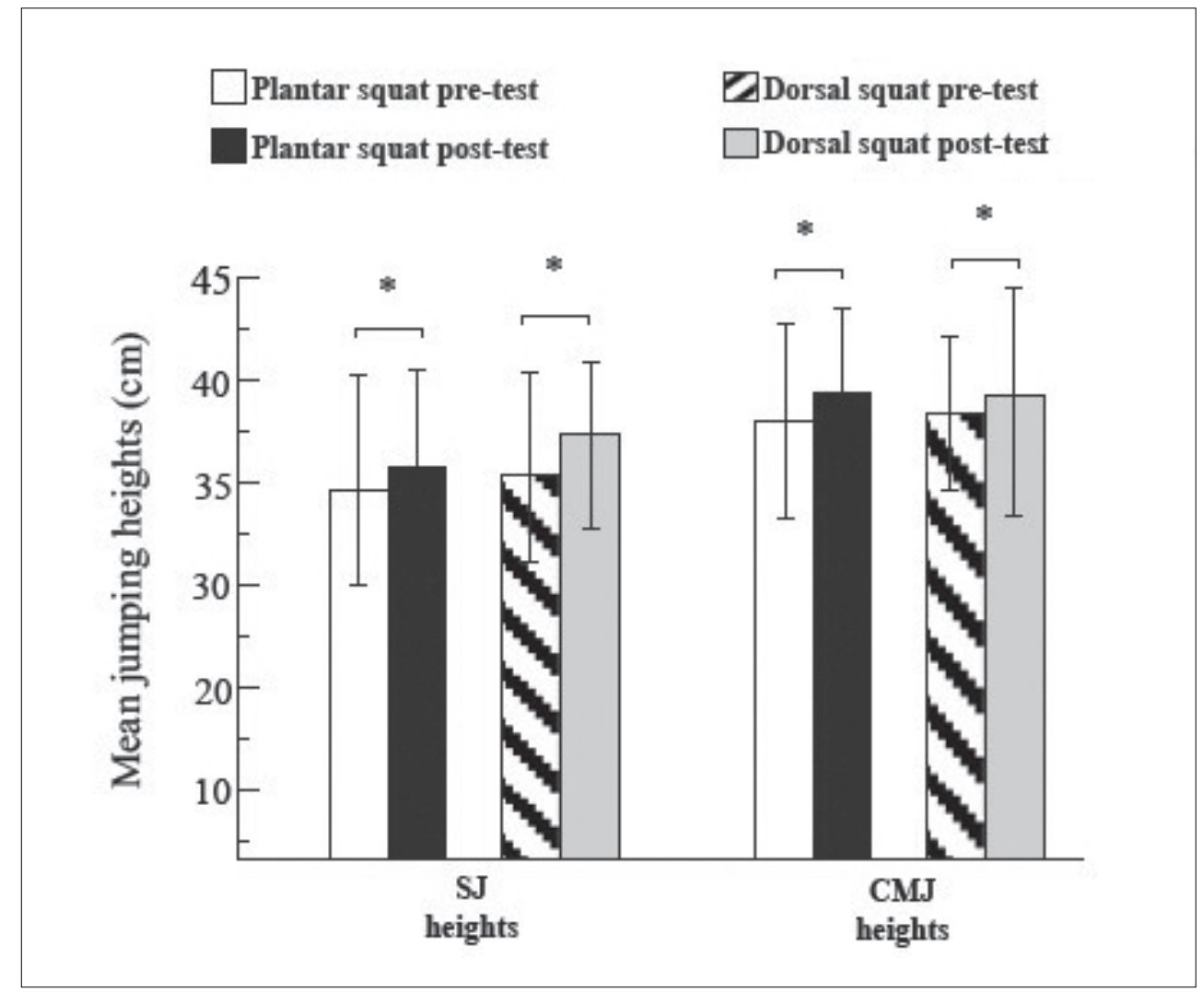

\section{DISCUSSION}

The main aim of this study was to determine whether there was an effect of WBV treatments with two different body positions on SJ and CMJ heights. The results indicate that there were no any differences between the plantar and dorsal flexion trials on SJ and CMJ heights, but WBV had a small though significant effect on SJ and CMJ jump heights by about $3 \%(1-2 \mathrm{~cm})$ after WBV conditioning at $26 \mathrm{~Hz}$ frequency regardless of body position. These results are in agreement with some previous studies. Bullock et al. (2008) found that there were no significant differences in jumping performance after acute application of WBV. Cardinale and Lim (2003) declared that 5 min, $20 \mathrm{~Hz}$ (low frequency) acute WBV significantly increased squat jump performance by $4 \%$. At $40 \mathrm{~Hz}$ 
(high frequency) they found a significant decrease in squat jump (-3.6\%) and in counter movement jump $(-3.8 \%)$ in untrained subjects. Cochrane and Stannard (2005) suggested that $26 \mathrm{~Hz}$ acute WBV increased vertical jump performance. Cormie, Deane, Triplett, \& Mcbride (2006) especially emphasized that $30 \mathrm{~Hz}$ acute WBV increased vertical jumping performance immediately following vibration. McBride et al. (2010) found that an acute bout of static, body weight squat exercises, combined with WBV, increased muscle force output up to 8 minutes post-exercise. Posjkic et al. (2015) remarked that additional external load of $30 \%$ bodyweight under WBV at $50 \mathrm{~Hz}, 4 \mathrm{~mm}$ posted superior gains in countermovement jump compared to unloaded WBV.

WBV stimulates plantar cutaneous afferents (Kavounoudias, R. Roll, \& J. P. Roll, 1999) and decrease in muscle length causes an increase in motor unit activity (Kennedy \& Cresswell, 2001). Muscle EMG activity decreases as the muscle is lengthened and muscle produces greater force in a lengthened state than in a shortened position (Lunnen, Yack, \& LeVeau, 1981) at $20^{\circ}$ of dorsal and $30^{\circ}$ plantar flexion (Vander Linden, Kukulka, $\&$ Soderberg, 1991). We did not reach joint angle at dorsal flexion conditions because of the difficulty of this angle during squat with WBV. The position with knees bent at $90^{\circ}$ with heels raised maximizes the vibration effect on vastus lateralis and lateral gastrocnemius muscles compared to no heel raised squat position (Di Giminiani, Masedu, Tihanyi, Scrimaglio, \& Valenti, 2013). However, the current study did not show differences between these two positions on jump performance. It can concluded that heel raised squat position during WBV does not have an acute effect on jumping heights according to our results. Regardless the squat position, WBV has a little acute effect $(\sim 1-2 \mathrm{~cm})$ on SJ heights during dorsal and plantar flexor squat position trials. According to these results it can be concluded that our WBV has a statistical effect on jumping, but muscle length during squat on vibration plate does not have any effect on jumping performance.

\section{CONCLUSION}

In conclusion, the current study showed that static squat position with different muscle length of plantar-flexors during $26 \mathrm{~Hz}$ WBV did not affect jumping heights compared with the noWBV condition. Practically, lower frequencies (20-30 Hz) (Cardinale \& Lim, 2003), 90 $0^{\circ}$ squat position (Avelar et al., 2013; Tsukahara et al., 2016) with heels raised (Di Giminiani et al., 2013) maximizes muscle activity and vibration effect, but squat position with or without heels raised has no effect on jump performance. Besides that WBV affects acute jump performance regardless of short or long muscle length during WBV. In our opinion, although WBV has an acute effect on jump performance, body position with different plantar flexor muscle length during WBV did not have any additional effect on athletic performance. However, further studies are needed to investigate the effect of WBV training using different positions, different vibration frequency and amplitude on field and laboratory exercise performance of lower limb.

\section{REFERENCES}

Abercromby, A. F. J., Amonette, W. E., Layne, C. S., B. K. Mcfarlin, B. K., Hinman, M. R., \& Paloski, W. H. (2007). Variation in neuromuscular responses during acute whole-body vibration exercise. Medicine \& Science in Sports \& Exercise, 39(9), 1642-1650. doi: 10.1249/mss.0b013e318093

Avelar, N. C., Ribeiro, V. G., Mezêncio, B., Fonseca, S. F., Tossige-Gomes, R., da Costa, S. J., ... Lacerda, A. C. R. (2013). Influence of the knee flexion on muscle activation and transmissibility during whole body vibration. Journal of Electromyography and Kinesiology, 23(4), 844-850. doi: 10.1016/j.jelekin.2013.03.014

Bosco, C., Cardinale, M., Tsarpela, O., Colli, R., Tihanyi, J., von Duvillard, S. P., \& Viru, A., (1998). The influence of whole body vibration on jumping performance. Biology of Sport, 15(3), 157-164.
Bosco, C., Colli, R., Introini, E., Cardinale, M., Tsarpela, O., Madella, A., ... Viru, A. (1999). Adaptive respsonses of human skeletal muscle to vibration exposure. Clinical Physiology-Oxford, 19, 183-187.

Bullock, N., Martin, D. T., Ross, A., Rosemond, C. D., Jordan, M. J., \& Marino, F. E. (2008). Acute effect of whole-body vibration on sprint and jumping performance in elite skeleton athletes. Journal of Strength and Conditioning Research, 22, 1371-1374. doi: 10.1519/ JSC.0b013e31816a44b5

Cardinale, M., \& Bosco, C. (2003). The use of vibration as an exercise intervention. Exercise and Sport Sciences Reviews, 31(1), 3-7.

Cardinale, M., \& Lim, J. (2003). The acute effect of two different whole body vibration frequencies on vertical jump performance. Medicine and Sport Science, 56, 287-292. 
Cochrane, D. J., Loram, I. D., Stannard, S. R., \& Rittweger, J. (2009). Changes in joint angle, muscletendon complex length, muscle contractile tissue displacement, and modulation of EMG activity during acute whole-body vibration. Muscle \& Nerve, 40(3), 420-429. doi: 10.1002/mus.21330

Cochrane, D. J., \& Stannard, S. R. (2005). Acute whole body vibration training increases vertical jump and flexibility performance in elite female field hockey players. British Journal of Sports Medicine, 39, 860865. doi:10.1136/bjsm.2005.019950

Cormie, P., Deane, R. S., Triplett, T., \& Mcbride, J. M. (2006). Acute effects of whole body vibration on muscle activity, strength, and power. Journal of Strength and Conditioning Research, 20(2), 257-261. doi: 10.1519/ R-17835.1

Di Giminiani, R., Masedu, F., Tihanyi, J., Scrimaglio, R., \& Valenti, M. (2013). The interaction between body position and vibration frequency on acute response to whole body vibration. Journal of Electromyography and Kinesiology, 23(1), 245-251. doi: 10.1016/j. jelekin.2012.08.018

Gojanovic, B., Feihl, F., Liaudet, L., Gremion, G., \& Waeber, B. (2011). Whole-body vibration training elevates creatine kinase levels in sedentary subjects. Swiss Medical Weekly, 141, w13222. doi: 10.4414/ smw.2011.13222

Kavounoudias, A., Roll, R., \& Roll, J. P. (1999). Specific whole-body shifts induced by frequency-modulated vibrations of human plantar soles. Neuroscience Letters, 266, 181-184.

Kennedy, P. M., \& Cresswell, A. G. (2001). The effect of muscle length on motor-unit recruitment during isometric plantar flexion in humans. Experimental Brain Research, 137(1), 58-64.

Lunnen, J. D., Yack, J., \& LeVeau, B. F. (1981). Relationship between muscle length, muscle activity, and torque of the hamstring muscles. Physical Therapy, 61(2), 190-195.

McBride, J. M., Nuzzo, J. L., Dayne, A. M., Israetel, M. A., Nieman, D. C., \& Triplett, N. T. (2010). Effect of an acute bout of whole body vibration exercise on muscle force output and motor neuron excitability. Journal of Strength and Conditioning Research, 24(1), 184-189. doi: 10.1519/JSC.0b013e31819b79cf

Pojskic, H., Pagaduan, J., Uzicanin, E., Babajic, F., Muratovic, M., \& Tomlijanovic, M. (2015). Acute effects of loaded whole body vibration training on performance. Asian Journal of Sports Medicine, 6(1), e24054. doi: 10.5812/asjsm.24054
Rittweger, J., Ehrig, J., Just, K., Mutschelknauss, M., Kirsch, K. A., \& Felsenberg, D. (2002). Oxygen uptake in whole-body vibration exercise: influence of vibration frequency, amplitude, and external load. International Journal of Sports Medicine, 23(6), 428-432. doi: 10.1055/s-2002-33739

Ritzmann, R., Gollhofer, A., \& Kramer, A. (2013). The influence of vibration type, frequency, body position and additional load on the neuromuscular activity during whole body vibration. European Journal of Applied Physiology, 113(1), 1-11. doi: 10.1007/s00421-0122402-0

Ritzmann, R., Kramer, A., Gruber, M., Gollhofer, A., \& Taube, W. (2010). EMG activity during whole body vibration: Motion artifacts or stretch reflexes? European Journal of Applied Physiology, 110(1), 143-151. doi: 10.1007/s00421-010-1483-x

Roelants, M., Verschueren, S. M., Delecluse, C., Levin, O., \& Stijnen, V. (2006). Whole-body-vibrationinduced increase in leg muscle activity during different squat exercises. The Journal of Strength \& Conditioning Research, 20(1), 124-129. doi: 10.1519/R-16674.1

Romaiguere, P., Vedel, J. P., Azulay, J. P., \& Pagni, S. (1991). Differential activation of motor units in the wrist extensor muscles during the tonic vibration reflex in man. The Journal of Physiology, 444(1), 645-667.

Torvinen, S., Kannu, P., Sievanen, H., Jarvinen, T. A., Pasanen, M., Kontulainen, S., ... Vuori, I. (2002). Effect of a vibration exposure on muscular performance and body balance. Randomized cross-over study. Clinical Physiology and Functional Imaging, 22(2), 145-152.

Tsukahara, Y., Iwamoto, J., Iwashita, K., Shinjo, T., Azuma, K., \& Matsumoto, H. (2016). What is the most effective posture to conduct vibration from the lower to the upper extremities during whole-body vibration exercise? Open Access Journal of Sports Medicine, 7, 5-10. doi: https://dx.doi.org/10.2147/OAJSM.S93047

Vander Linden, D. W., Kukulka, C. G., \& Soderberg, G. L. (1991). The effect of muscle length on motor unit discharge characteristics in human tibialis anterior muscle. Experimental Brain Research, 84(1), 210-218. 